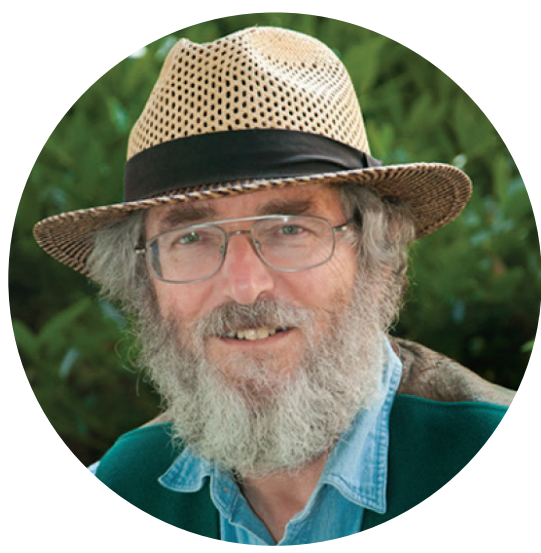

Public health in the 21st century

\title{
Governance for a
} healthy, just and sustainable future

${ }^{66} \mathrm{~S}$ alus populi suprema lex esto" - the health of the people is the supreme law wrote Cicero in about $44 \mathrm{BC}$. The masthead of The Sanitarian, a 19th-century public health journal, stated, "A Nation's Health is a Nation's Wealth." The logic of this series of columns leads to this: if the health of the people really were the supreme law, how then should we govern ourselves? In answering this question, public health provides a radical critique of our current economic and governance systems, and suggests a distinct alternative.

Governance is the process by which we make decisions, and involves far more than just the government. It should be a collaborative community and societal process involving the public, private, nonprofit and community sectors and individuals working together for a common purpose.

But what is that purpose? What

Trevor Hancock MBBS MHSc

Cite as: CMAJ 2018 May 22;190:E634. doi: $10.1503 / \mathrm{cmaj} .180588$

Dr. Trevor Hancock is an internationally recognized public health physician. He was one of the creators of the global Healthy Cities and Communities movement, and he cofounded both the Canadian Association of Physicians for the Environment and the Canadian Coalition for Green Health Care. He's a senior editor for the Canadian Journal of Public Health, on the editorial board of Cities \& Health and a columnist for a daily newspaper in Victoria, BC. The Canadian Public Health Association recently recognized his outstanding contributions in the broad field of public health with the R.D. Defries Award. business are we in - or, more to the point, should we be in? From a public health perspective, our purpose should be to maximize the health and well-being of the entire population, and to improve quality of life and the level of human development and happiness. The latter, as the 2017 World Happiness Report notes, "is increasingly considered the proper measure of social progress and the goal of public policy." All this must be done within the natural constraints imposed by the physical and ecological limits of this one small planet upon which we live.

However, in practice, that is not what modern-day societies focus on. Instead, their focus is on economic development and growth of gross domestic product (GDP), which is equated - confused, really - with social progress. This, despite the fact that one of the key architects of the GDP, Simon Kuznets, warned the US Congress in 1934 that "the welfare of a nation can scarcely be inferred from a measure of national income."

Gross domestic product is misleading because it largely comprises both harmful activities - such as those of the tobacco, junk food or polluting industries - and expenditures on protection, clean-up, repair and restoration; think of the health system costs for treating the related diseases. In addition, the pursuit of GDP growth has led to the rapidly emerging ecological crisis we now face and has created high levels of economic and social inequality, with important adverse health and social impacts.

Public health must necessarily stand in opposition to any and all policies and practices in the public or private sector that harm health. This means not only the simple and obvious opposition to the tobacco, junk food and related industries, but the more profound need to oppose fossil fuels and other industries that threaten the stability and sustainability of the natural ecosystems that support our life and health. We must either ban or control all economic activities that harm health - and the list is long. And we must support and encourage industries that make money while also increasing human and social development and our ecological sustainability.

Fundamentally, we must oppose the current economic system and offer in its place what E.F. Schumacher called, in his 1973 book Small is Beautiful, "a system of economics as if people (and the planet) mattered." More than mere economics, we need to "redefine the growth narrative to put people's well-being at the centre of governments' efforts," as the Organisation for Economic Co-operation and Development committed to do in 2016, using new measures of progress such as the Genuine Progress Index or the Canadian Index of Wellbeing.

Doing this will require redesign of our constitutional, democratic and legal systems to protect and promote such values (e.g., giving "personhood" to ecosystems - as has begun in New Zealand and elsewhere - while denying it to corporations), and broadening citizen engagement in identifying problems and finding solutions. This would create a system of governance that seeks to create healthy people in healthy communities in a healthy world, which is a pretty good definition of the business of public health in the 21st century, and well worth fighting for. 